University of Nebraska - Lincoln

DigitalCommons@University of Nebraska - Lincoln

Papers in the Earth and Atmospheric Sciences

Earth and Atmospheric Sciences, Department

\title{
Ground-Based Thermography of Fluvial Systems at Low and High Discharge Reveals Potential Complex Thermal Heterogeneity Driven by Flow Variation and Bioroughness
}

\author{
M. Bayani Cardenas \\ University of Texas at Austin \\ Judson W. Harvey \\ U.S. Geological Survey, Reston, Virginia \\ Aaron I. Packman \\ Northwestern University \\ Durelle T. Scott \\ University of Nebraska-Lincoln
}

Follow this and additional works at: https://digitalcommons.unl.edu/geosciencefacpub

Part of the Earth Sciences Commons

Cardenas, M. Bayani; Harvey, Judson W.; Packman, Aaron I.; and Scott, Durelle T., "Ground-Based Thermography of Fluvial Systems at Low and High Discharge Reveals Potential Complex Thermal Heterogeneity Driven by Flow Variation and Bioroughness" (2008). Papers in the Earth and Atmospheric Sciences. 82.

https://digitalcommons.unl.edu/geosciencefacpub/82

This Article is brought to you for free and open access by the Earth and Atmospheric Sciences, Department of at DigitalCommons@University of Nebraska - Lincoln. It has been accepted for inclusion in Papers in the Earth and Atmospheric Sciences by an authorized administrator of DigitalCommons@University of Nebraska - Lincoln. 


\title{
Ground-based thermography of fluvial systems at low and high discharge reveals potential complex thermal heterogeneity driven by flow variation and bioroughness
}

\author{
M. Bayani Cardenas, ${ }^{1 *}$ Judson W. Harvey, ${ }^{2}$ Aaron I. Packman ${ }^{3}$ and Durelle T. Scott ${ }^{4}$ \\ ${ }^{1}$ Department of Geological Sciences, The University of Texas at Austin, Austin, Texas, USA \\ ${ }^{2}$ U.S. Geological Survey, Reston, Virginia, USA \\ ${ }^{3}$ Department of Civil Engineering and Environmental Engineering, Northwestern University, Evanston, Illinois, USA \\ 4 Department of Geosciences, University of Nebraska-Lincoln, Lincoln, Nebraska, USA
}

\begin{abstract}
:
Temperature is a primary physical and biogeochemical variable in aquatic systems. Field-based measurement of temperature at discrete sampling points has revealed temperature variability in fluvial systems, but traditional techniques do not readily allow for synoptic sampling schemes that can address temperature-related questions with broad, yet detailed, coverage. We present results of thermal infrared imaging at different stream discharge (base flow and peak flood) conditions using a handheld IR camera. Remotely sensed temperatures compare well with those measured with a digital thermometer. The thermal images show that periphyton, wood, and sandbars induce significant thermal heterogeneity during low stages. Moreover, the images indicate temperature variability within the periphyton community and within the partially submerged bars. The thermal heterogeneity was diminished during flood inundation, when the areas of more slowly moving water to the side of the stream differed in their temperature. The results have consequences for thermally sensitive hydroecological processes and implications for models of those processes, especially those that assume an effective stream temperature.
\end{abstract}

KEY WORDS thermography; temperature; river; periphyton; wood; sand

Received 8 June 2007; Accepted 15 October 2007

\section{INTRODUCTION}

Temperature is a primary variable that drives physical, ecological, and biogeochemical processes in aquatic systems and controls habitat diversity (Hynes, 1970; Ward, 1985; Poole and Berman, 2001). The thermal regime of streams is complex in space and time, especially when several sources of thermal energy are present, such as groundwater flow (Webb and Zhang, 1999; Poole and Berman, 2001). Nevertheless, most previous studies have relied on a few point measurements and assume this as a representative value used for interpretative purposes and in process-based and empirical-statistical ecological models (e.g. Morin et al., 1999; Karlsson et al., 2005; Kishi et al., 2005). Distributed point measurements of temperature are easily acquired and are becoming less expensive (e.g. Johnson et al., 2005; Selker et al., 2006), but improving point-sensor technology does not address the need for broad yet very high-resolution aerialcoverage studies to characterize spatial complexity in thermal regimes of surface water and their implications for ecological processes.

A useful method for synoptic sampling of temperature is through remote sensing, i.e. thermal IR imagery or thermography. Airborne thermography from helicopters

* Correspondence to: M. Bayani Cardenas, Department of Geological Sciences, The University of Texas at Austin, Austin, Texas, USA.

E-mail: cardenas@mail.utexas.edu has provided accurate estimates of stream-surface temperature with decimeter-scale resolution (e.g. Torgersen et al., 2001; Loheide and Gorelick, 2005). Ground-based methods can potentially allow for increased resolution along with real-time imaging, and can therefore provide information that may be necessary for designing or adapting synchronous field experiments. For example, the technique allows for rapid assessment of hotspots during short-lived events, such as floods, providing critical information for sampling design and perhaps opportunistic research. Increased spatial resolution also allows for mapping temperature variability in zones commonly considered as homogeneous. We explore the potential advantages and pitfalls of ground-based thermography with a handheld camera and present preliminary observations. Our survey was conducted when other related experiments were being conducted at Maple Creek near Nickerson, Nebraska, USA in September 2006 to study biogeochemical and hydrologic in-stream processes. The duration of this study covered a rainfall event, which led to a substantial increase in stream depth and discharge (Figure 1).

\section{METHODS}

Water temperature can be remotely detected by a sensor that receives thermal radiation emitted from surfaces of objects (Anderson and Wilson, 1984). Emitted (and 
absorbed) radiation is strongly dependent on the emissivity of the object: the ratio of emittance between an object and a black body at equal temperatures. For water surfaces, which have an emissivity of $\sim 0.95-0.97$, this technique is sensitive to the temperature of the upper $0.1 \mathrm{~mm}$ of the water column (Anderson and Wilson, 1984). Another factor important in thermal imagery is atmospheric absorption that can be taken into account when relative humidity, temperature, and the length of the atmospheric column (essentially the distance) between the detector and target object are all known. Atmospheric adsorption of radiation is pronounced when water vapour is high, and is negligible at low humidity and/or when measurement distances are short (Anderson et al., 1995). Sensors for thermal imagery also detect reflected radiation from other sources (Figure 1 in Torgersen et al. (2001)).

Handcock et al. (2006) has provided a thorough evaluation of measurement error and uncertainty associated with space-borne, airborne, and ground-based methods. Airborne-based thermal images that have at least 3 pixels of the stream resolved are within $1.2{ }^{\circ} \mathrm{C}$ of ground measurements with temperature probes. The accuracy of remotely-sensed temperatures decreases when there is substantial sub-pixel variability in temperature. For example, Handcock et al. (2006) showed that the difference between probe and remotely-sensed temperature estimates can be as high as $7.6^{\circ} \mathrm{C}$ when the stream is only a fraction of a pixel and the detector mixes the signals from the banks with that from the river. In our case, we have tens if not hundreds of pixels covering the stream. Following Handcock et al. (2006) observations, our ground-based imaging on the scale of a few metres would be able to accurately resolve temperature variability with spatial scales in the order of $\sim 1 \mathrm{~cm}$.

Thermal images were taken with a FLIR Systems P65 camera (North Billerica, MA, USA), with a spectral range of 7.5-13 $\mu \mathrm{m}$, mounted on a tripod located at the bank of the stream, and later in the stream during peak discharge when the exposed bank became inundated. The lens used for thermal imaging has a $19^{\circ} \times 14^{\circ}$ field-of-view with a minimum focal length of $0.3 \mathrm{~m}$, allowing for centimetreto-millimetre resolution. The IR camera includes a visual camera that can take concurrent optic images, but with relatively low resolution. Thermal images have $320 \times$ 420 pixels and optic images have $640 \times 480$ pixels. The detected radiant temperature has an accuracy of $\pm 2 \%$ of the reading. Meteorological data were collected from the nearest station where the appropriate information is available. Air temperature was taken from a U. S. Geological Survey National Water Information System station (Maple Creek near Nickerson, Nebraska, ID $06800000)$ located a few $100 \mathrm{~m}$ downstream of the study reach, precipitation was taken from another USGSNWIS station (Logan Creek near Uehling, Nebraska, ID 06799500 ) about $15 \mathrm{~km}$ north of the site, and relative humidity was taken from the Fremont Municipal Airport in Nebraska (data from National Climatic Data Center). Emissivity in all the images was assumed constant at $0 \cdot 96$. This may lead to errors where the emissivity of the objects in the field-of-view are far from that of water, but the main interest here is in the distribution of water temperature. Image processing was conducted

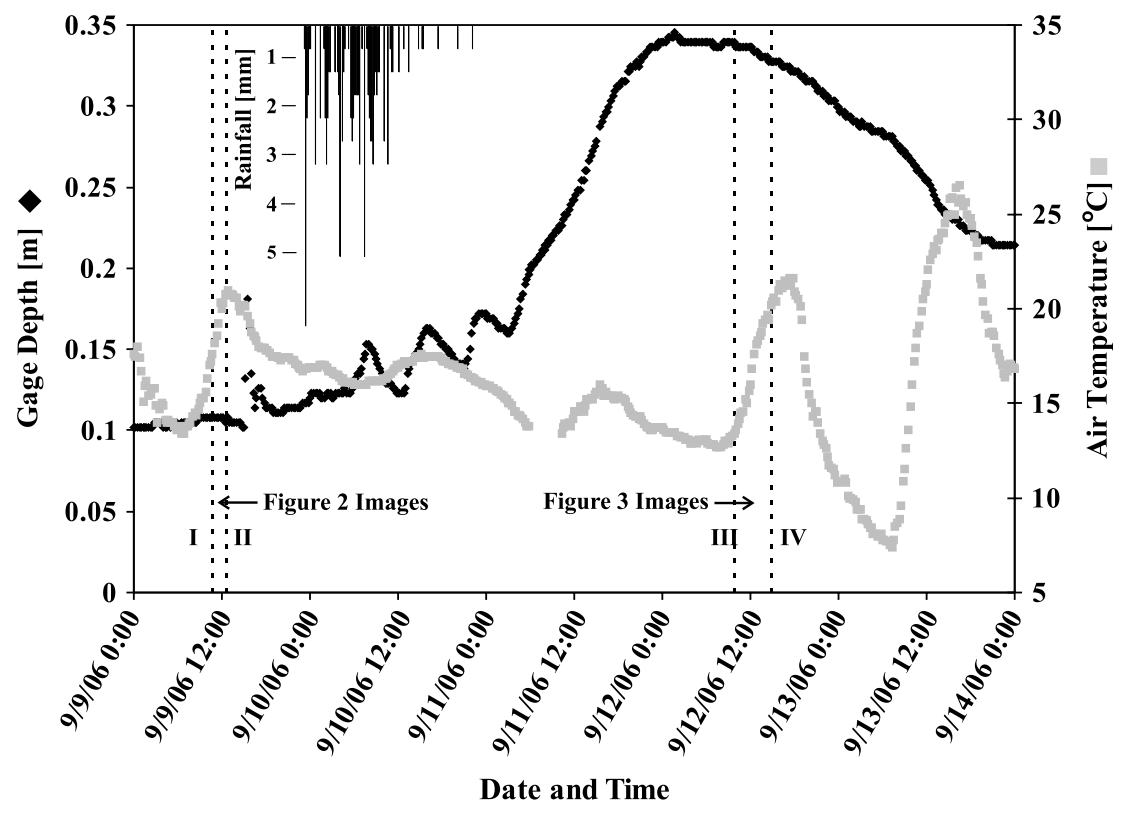

Figure 1. Weather and stage data for study site in Maple Creek, Nebraska during experiments. Air temperature (grey squares) is from Maple Creek near Nickerson station (United States Geological Survey/National Water Information System ID 06800 000, unprocessed data). Precipitation is from Logan Creek near Uehling station (United States Geological Survey/National Water Information System ID 06799 500, unprocessed data), which is about $20 \mathrm{~km}$ north of the study but within the same watershed. Depth was recorded by a probe nominally located about $250 \mathrm{~m}$ downstream of the site portrayed in Figures 2 and 3. Discharge was manually measured with a flowmeter, resulting in a stage-discharge rating curve (not shown). Vertical dashed lines labelled by Roman numerals indicate times when images presented in Figures 2 and 3 were taken. The discharge for these times, based on the rating curve that we developed, are approximately $\mathrm{I}=66 \cdot 0 \mathrm{~L} / \mathrm{s}, \mathrm{II}=66 \cdot 0 \mathrm{~L} / \mathrm{s}, \mathrm{III}=1174 \cdot 3 \mathrm{~L} / \mathrm{s}$, and IV $=1114 \cdot 1 \mathrm{~L} / \mathrm{s}$ 
using ThermaCAM Researcher Pro 2.8 software, also distributed by FLIR Systems (2004).

Several images were collected between 9 and 12 September. We present images collected at two times on 9 September 2006 (Figure 2, see Figure 1 for timing), during base-flow conditions in Maple Creek, and at two other times on September 12, 2006 (Figure 3), just after peak flood discharge. These images are off-vertical. Direct measurements of temperature were collected with a Beckman temperature probe (Model BK598115, Fullerton, CA, USA) with a resolution of $0 \cdot 1{ }^{\circ} \mathrm{C}$ and a relative accuracy of $\pm 1 \%$ of the reading. The manual measurement points are indicated by labelled crosses in Figures 2 and 3. Ground-truth points were located in the water, a periphyton community, and in a partially submerged sandbar. Direct temperature measurements were taken at shallowest possible depths, typically the upper $3 \mathrm{~cm}$, within seconds to a few minutes after the thermal IR images were taken. Table I compares radiant temperatures detected by the camera versus the kinetic temperature measured with the thermometer. The absolute differences are less than or equal to $0.5^{\circ} \mathrm{C}$ in all cases, similar in magnitude to those reported in Torgersen et al. (2001) and Loheide and Gorelick (2005). The pixels were matched to the measurement points based on visual observation; this could affect the comparisons especially within the periphyton.

\section{RESULTS AND DISCUSSION}

Figure 2 illustrates the degree of thermal heterogeneity present along a small section of a stream. The portion of the channel shown in Figure 2 (top) is roughly $3 \mathrm{~m}$ wide, with the flow from right to left. The images taken later that same day (bottom of Figure 2) show a portion of the same area but from a closer and different perspective (although the downstream direction always remains to the left). The top image in Figure 2 looks more directly downstream while the bottom image is taken from beside the stream facing the exposed log (bright or warm zone) that is centrally located in the top image. Note that the temperature scales are different for the top and bottom images. Stream temperatures increased throughout the day due to incoming solar radiation, i.e. insolation and increasing air temperature.
Figure 2 shows that water flowing through periphyton anchored on the streambed becomes significantly warmer than the fast-flowing portions of channel, resulting in pronounced thermal gradients within and around the algal mats. The temperature within the periphyton was quite patchy, especially later in the day. Temperature observed within the periphyton covers a range of $\sim 3^{\circ} \mathrm{C}$. The patchiness is probably due to differences in thickness of the periphyton or local differences in the velocity of water flow through the mats or both. Unfortunately, neither of these potential causes for temperature differences, which may act in tandem, were directly measured. Differences in periphyton thickness were readily visible. Injection of rhodamine dye revealed that local velocities were much less in extensive algal mats compared to the main channel, consistent with observed exponential flow deceleration within periphyton assemblages (Dodds and Biggs, 2002). Storage timescales of stream water in periphyton mats tend to be on the order of minutes to tens of minutes (Kim et al., 1990). A similar storage time was observed for the rhodamine injection. Flow extinction within periphyton is proportional to mass density (Dodds and Biggs, 2002). The variable thickness of the monitored periphyton therefore leads to a heterogeneous velocity field. However even if heat advection were minimal to absent, which is not the case here, heat conduction would also be different when some areas of the mat are thinner or thicker than others. Moreover, differences in thermal mass could, by itself, lead to differential heating even if the periphyton surface was exposed to the same solar radiation and the entire mat volume exposed to the same advective flux per unit volume. If transport of thermal energy away from the periphyton cannot balance continued or increasing input of thermal energy, such as insolation, the mat would warm up. Our observations are the result of all the processes above, with the differential transport and storage of heat ultimately resulting in the thermal heterogeneity. Note that the emissivity of the exposed periphyton may be different to that of water. This could lead to some of the observed thermal heterogeneity. However, we could not find information on the emissivity of periphyton in streams.

Empirical data and ecological models show temperature sensitivity of periphyton productivity (e.g. Morin et al., 1999; Karlsson et al., 2005; Kishi et al., 2005).

Table I. Comparison of temperature measurements $\left({ }^{\circ} \mathrm{C}\right)$ between thermal infrared camera and digital temperature probe

\begin{tabular}{lcccc}
\hline Date and time & Location & Camera & Probe & Abs. diff. \\
\hline 9/9/2006 12:44 & Sand bar (A) ${ }^{\mathrm{a}}$ & $21 \cdot 6$ & $21 \cdot 5$ & $0 \cdot 1$ \\
& Active channel (B) $^{\mathrm{a}}$ & $17 \cdot 9$ & $17 \cdot 6$ & $0 \cdot 3$ \\
9/12/2006 12:40 & Periphyton (C) & $19 \cdot 0$ & $18 \cdot 6$ & $0 \cdot 4$ \\
& ${\text { Downstream of } \log (\mathrm{D})^{\mathrm{b}}}^{\mathrm{a}}$ & $20 \cdot 2$ & $20 \cdot 6$ & $0 \cdot 4$ \\
9/12/2006 16:10 & Upstream of log (E) $^{\mathrm{b}}$ & $20 \cdot 4$ & $20 \cdot 8$ & $0 \cdot 4$ \\
& Upstream of log & $21 \cdot 7$ & $22 \cdot 2$ & $0 \cdot 5$ \\
& Downstream of log & $22 \cdot 2$ & $22 \cdot 3$ & $0 \cdot 1$ \\
\hline
\end{tabular}

\footnotetext{
a Approximate location shown in Figure 2.

${ }^{\mathrm{b}}$ Approximate location shown in Figure 3.
} 

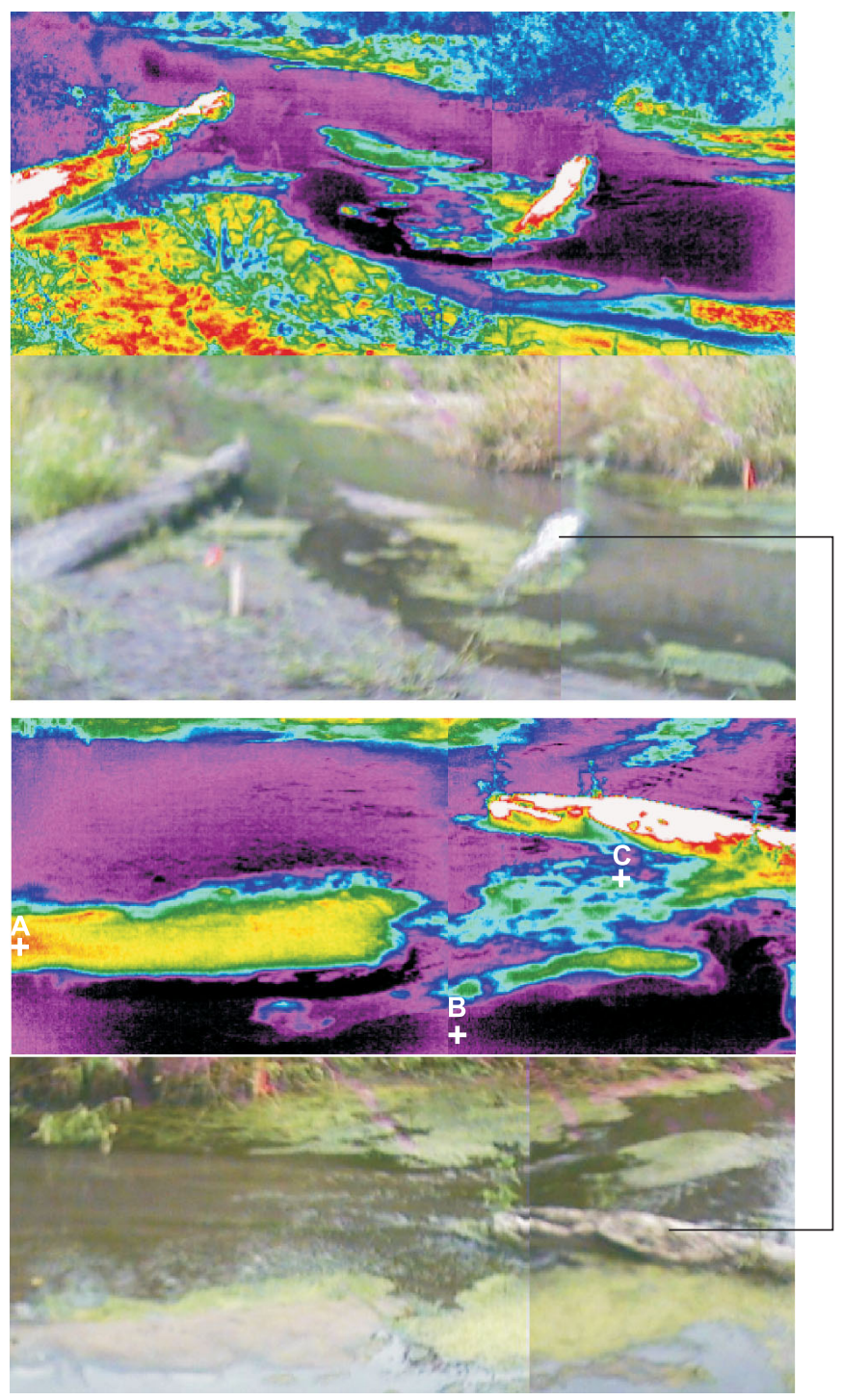

Sep. 9, 2006

$10: 36 \mathrm{AM}$

$Q=66.0 \mathrm{~L} / \mathrm{s}$

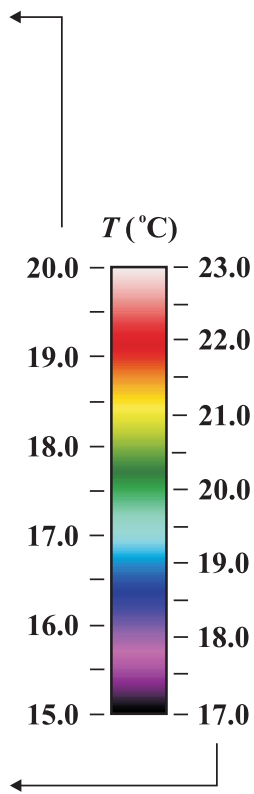

Sep. 9, 2006

12:44 PM

$Q=66.0 \mathrm{~L} / \mathrm{s}$

Figure 2. Thermal infrared (top) and corresponding visual images (immediately below the thermal image) taken on 9 September2006 during low-discharge stage. The partially exposed log is roughly a metre long. Timing of images indicated by dashed lines in Figure 1 . For reference, the same $\log$ is connected by a line in the visual images. Temperature measurements at A, B, and C are presented in Table I

Ecological models of periphyton are either based on correlation with stream temperature or consider stream temperature as one of several key variables. Given the sensitivity of periphyton to temperature, our results suggest the need for more detailed studies on the role of coupled water flow and heat transfer in the development of periphyton communities. For example, Hill and Boston (1991) illustrated that vertical accumulation in old periphyton communities leads to photo inhibition of deeper portions of the periphyton, thereby affecting photosynthesis and growth. Others have investigated the combined effects of vertical heterogeneity in biomass and nutrients within the periphyton mat, in addition to variability in light irradiance (Asaeda and Son, 2001). Some studies have also shown that periphyton metabolism is directly related to the surrounding water velocity under isothermal conditions (Hondzo and Wang, 2002). Our thermal images suggest that temperature, which also controls metabolic processes and trophic transfer, also varies significantly within periphyton mats.
A partially exposed sandbar showed similar internal variability in temperatures of up to $\sim 3^{\circ} \mathrm{C}$ and large thermal gradients (Figure 2). The sandbar warmed up more than the periphyton, possibly due to less efficient export of heat and longer residence times for water advecting heat into and out of the sandbar. The warming of the exposed section of the sandbar will undoubtedly propagate into partially saturated sediments and finally to the saturated sediments below the water table that are part of the hyporheic zone. Past studies of propagation of periodic temperature signals (e.g. diurnal or seasonal) into river sediments are typically based on considering the stream water temperature as the top boundary (Anderson, 2005; Cardenas and Wilson, 2007). Our observations suggest that the thermal regime of partially exposed sediments is more complex, with the banks of the sandbars in thermal equilibrium with the river water, while the tops are more sensitive to direct solar energy inputs. Note that the emissivity of sand according to Cuenca and Sobrino (2004), $0 \cdot 955$, is close to that used in our analysis (0.96). 
However, other factors not included in this analysis, such as soil mineralogy and organic matter content, may also affect the emissivity of sand (e.g. O'Neill and Jackson, 1990), thereby changing the calculated radiant temperature. These were not considered.

Partially exposed logs in Figure 1 show significantly higher temperatures. The temperatures in the logs are actually higher than the range shown (up to as high as $29^{\circ} \mathrm{C}$ in some spots). The displayed range was truncated to best illustrate the variability within the channel itself. The emissivity of manufactured wood $(0.80-0.92)$ is lower than that of water or water-saturated sediments (Childs, 2001; Rice, 2004), but the emissivity for bark 0.93-0.97, http://www.icess.ucsb.edu/modis/EMIS/html/ em.html (MODIS Emissivity Library, 2007) is similar to the value used here. Using the lowest emissivity value changes the radiant temperature by less than $1{ }^{\circ} \mathrm{C}$. Logs therefore may contribute to thermal heterogeneity of fluvial corridors and may be an important factor in determining in-stream energy budgets.

Maple Creek's watershed received about $5 \mathrm{~cm}$ of rain over the course of less than $24 \mathrm{~h}$ (10 September 2006) leading to a significant increase in discharge (Figure 1). Figure 3 shows thermal images taken close to the maximum discharge for this event. The vantage point for these images is similar to that in the bottom panel of Figure 2. The images show a portion of the larger log, now mostly submerged, exposed downstream in Figure 2 (left panels in Figure 3); the large water ripple in the right panels in Figure 3 is due to the smaller upstream $\log$ in Figure 2, now completely submerged. No periphyton or sandbars are visible, and postflood observations indicated that the periphyton was detached by the high-stream velocity and transported downstream. Periphyton beds and small sandbars do not contribute to thermal heterogeneity in the channel during higher stream discharge, although larger roughness features continue to be important. The $\log$ in Figure 3 is still associated with pronounced warming during the day, and on the far side of the stream a bank that projects into the flow during higher discharge appears to shelter an area of lower flow velocity and higher temperature at midday. The contrast in thermal heterogeneity between baseflow and flood conditions illustrates the strong coupling between discharge and thermal heterogeneity. Doyle et al. (2005) recently adapted the concept of effective discharge, the discharge corresponding to the prevailing geomorphologic imprint, to stream ecology. They calculated the discharge at which certain ecological variables will be significantly altered and showed that the greatest accumulation of periphyton is limited to a narrow discharge range. The increased discharge at Maple Creek clearly modified the thermal pattern in the stream by surpassing certain discharge thresholds, i.e. for periphyton removal as well as for sandbar erosion or submergence, but not for others, i.e. mobilization of the larger logs shown in Figure 2.

Thermal heterogeneity may have a complicated relationship with discharge if several differing sources of thermal signals are present. Thermal heterogeneity in fluvial corridors is commonly tied to spatial variability in hydrological or meteorological forcing. Arscott et al. (2001) found that thermal heterogeneity within a braided river corridor was pronounced in the lowland floodplains and less so in the main channel. This behaviour was attributed to differences in hydrologic connections between channels, ponds, tributaries, and subsurface flowpaths. Uehlinger et al. (2003) illustrated how thermal heterogeneity within the floodplain of a glacial river was connected to meltwater discharge. The studied river illustrated pronounced thermal heterogeneity, with surface-connected channels cooling consistently due to incoming colder meltwater, and surface-disconnected channels warming up due to increasing insolation. Johnson (2004) discussed the effects of shading of the channel and the characteristics of the sediments lining the channel on stream temperatures. The different external (meteorological) and internal (mostly hydrological) drivers of in-stream temperature were recently reviewed by Poole and Berman (2001). It is notable that the only biological mechanisms affecting in-stream temperature and heat budgets that were discussed are those related to riparian vegetation. Our thermal imagery, although preliminary in nature, resulted in rapid and detailed identification of the potential importance of biological as well as physical sources of thermal heterogeneity - periphyton, logs and partially exposed sandbars - that have not been considered in past studies.

\section{COMMENTS AND RECOMMENDATIONS}

Although thermal IR imagery has several advantages, there are limitations that need to be considered. We found that in certain instances, emitted radiation from personnel walking along the bank reflected off the water surface and appeared as originating from the channel dominating the signal received by the camera (results not shown). This was also observed earlier by Handcock et al. (2006). Additionally, irregular incident angle resulting from the water surface roughness affects emissivity (Masuda et al., 1988), but this effect has been quantified not to be very significant (Cuenca and Sobrino, 2004). The combined effects of reflected radiation and emissivity variation are evident in Figure 3 where temperature patterns are clearly associated with the water surface ripples. Such effects are potentially interesting from the perspective of quantifying stream water surface roughness (Torgersen et al., 2001) but may cause problems in retrieving accurate remotely sensed temperatures. These problems may be minimized by near-vertical viewing; but then this would typically require airborne platforms, which remove the advantages of acquiring real-time high-resolution images, or establishing infrastructure above the stream if long-term monitoring is desired. Bridges may be useful platforms but they could potentially contribute to unwanted shading of the study sites. Turbidity also affects emissivity (Liu et al., 1987). Maple Creek was clearly more turbid during the flood (Figure 3) but the effects of the differing turbidity levels were not determined. Lastly, it needs 

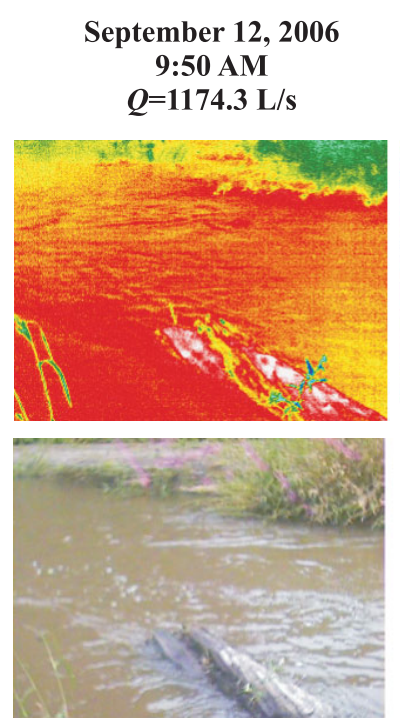

September 12, 2006
12:40 PM
$Q=1114.1 \mathrm{~L} / \mathrm{s}$
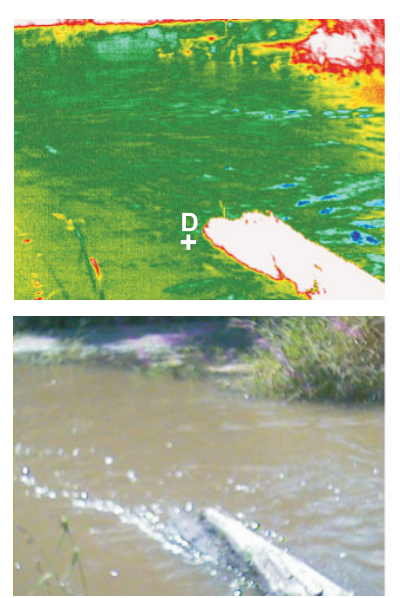
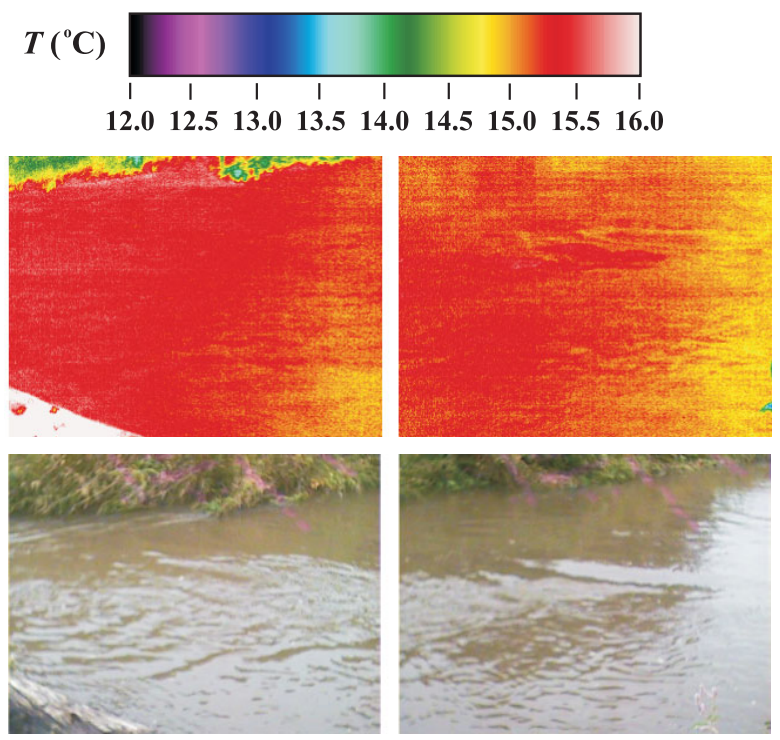

$T\left({ }^{\circ} \mathrm{C}\right)$
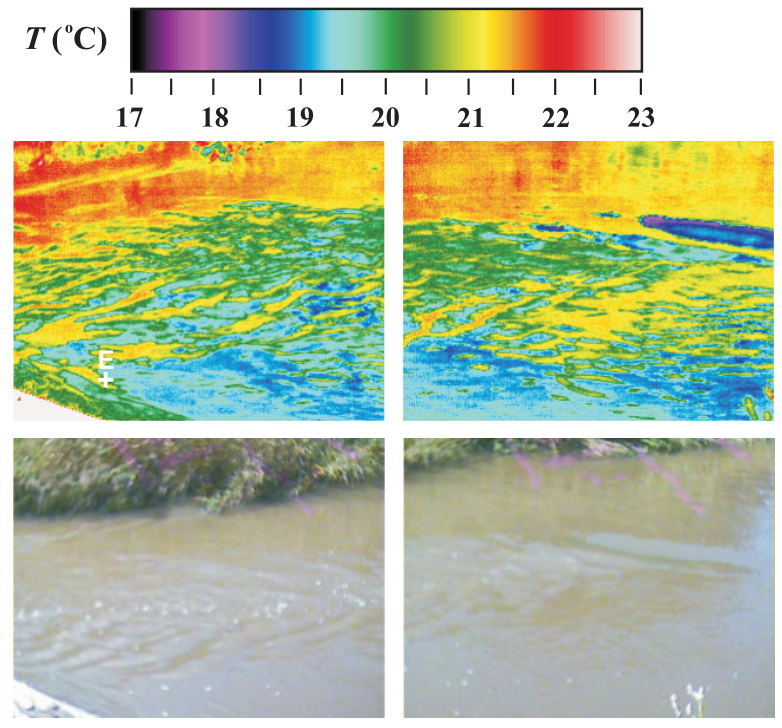

Figure 3. Thermal infrared and visual images taken on 12 September 2006 during high-discharge stage. The partially exposed log is roughly a metre long. Images are not exactly on the same scale and are only approximately from the same vantage point. Timing of images indicated by dashed lines in Figure 1. Temperature measurements at $\mathrm{D}$ and $\mathrm{E}$ are presented in Table I

to be emphasized that thermal IR imagery is sensitive only to skin temperatures that may not be representative of water column temperatures when the water bodies are not vertically well-mixed.

Aside from the difficulties discussed above and in previous sections of this paper, ground-based thermography of streams using a handheld camera offers realtime acquisition of high-quality temperature information and broad areal coverage. Further application of groundbased thermography will result in new data sets that are amenable for more quantitative spatial analysis. These data sets can provide answers to old research questions that have been difficult to address with traditional methods, and also open new avenues in studies of coupled hydrological, ecological, and biogeochemical processes.

\section{ACKNOWLEDGEMENTS}

This research is partially funded by the University of Texas-Department of Geological Sciences William T.
Stokes Centennial Teaching Fellowship held by MBC. Additional support from the U.S. Geological Survey's National Research Program and U.S. National Science Foundation Grant EAR-0408744 to AIP and JWH is also gratefully acknowledged. We thank Dan Nowacki of the USGS for analysing the stream discharge data. Comments from three anonymous reviewers and Guest Editor David Hannah are acknowledged.

\section{REFERENCES}

Anderson MP. 2005. Heat as a groundwater tracer. Ground Water 43: 951-968.

Anderson JM, Wilson SB. 1984. The physical basis of current infrared remote-sensing techniques and the interpretation of data from aerial surveys. International Journal of Remote Sensing 5: 1-18.

Anderson JM, Duck RW, McManus J. 1995. Thermal radiometry: a rapid means of determining surface water temperature variations in lakes and reservoirs. Journal of Hydrology 173: 131-144.

Arscott DB, Tockner K, Ward JV. 2001. Thermal heterogeneity along a braided floodplain river (Tagliamento River, northeastern Italy). Canadian Journal of Fisheries and Aquatic Sciences 58: 2359-2373. 
Asaeda T, Son DH. 2001. A model of the development of a periphyton community: resource and flow dynamics. Ecological Modelling 137: $61-75$.

Cardenas MB, Wilson JL. 2007. The effects of current-bedform induced fluid flow on the thermal regime of sediments. Water Resources Research 43: W08 431, Doi:10·1029/2006WR005343.

Childs PRN. 2001. Practical Temperature Measurement. ButterworthHeinemann: Oxford, UK

Cuenca J, Sobrino JA. 2004. Experimental measurements for studying angular and spectral variation of thermal infrared emissivity. Applied Optics 43: 4598-4602.

Dodds WK, Biggs BJF. 2002. Water velocity attenuation by stream periphyton and macrophytes in relation to growth form and architecture. Journal of the North American Benthological Society 21: 2-15.

Doyle MW, Stanley EH, Strayer DL, Jackson RB, Schmidt JC. 2005. Effective discharge analysis of ecological processes in streams. Water Resources Research 41: W11 411, Doi:10/1029/2005WR004222.

FLIR Systems. 2004. ThermaCAM Researcher User's Manual. FLIR Systems: Billerica, Massachussetts.

Handcock RN, Gillespie AR, Cherkauer KA, Kay JE, Burges SJ, Kampf SK. 2006. Accuracy and uncertainty of thermal-infrared remote sensing of stream temperatures at multiple spatial scales. Remote Sensing of Environment 100: 427-440.

Hill WR, Boston HK. 1991. Community development alters photosynthesis-irradiance relations in stream periphyton. Limnology and Oceanography 36: 1375-1389.

Hondzo M, Wang H. 2002. Effects of turbulence on growth and metabolism of periphyton in a laboratory flume. Water Resources Research 38: 1277, Doi:10·1029/2002WR001409.

Hynes HBN. 1970. The Ecology of Running Waters. University of Toronto Press: Toronto, Canada.

Johnson SL. 2004. Factors influencing stream temperatures in small streams: substrate effects and a shading experiment. Canadian Journal of Fisheries and Aquatic Sciences 61: 913-923.

Johnson AN, Boer BR, Woessner WW, Stanford JA, Poole GC, Thomas SA, O'Daniel SJ. 2005. Evaluation of an inexpensive smalldiameter temperature logger for documenting ground water-river interactions. Ground Water Monitoring and Remediation 25: 68-74.

Karlsson OM, Richardson JS, Kiffney PM. 2005. Modelling organic matter dynamics in headwater streams of south-western British Columbia, Canada. Ecological Modelling 183: 463-476.

Kim BK, Jackman AP, Triska FJ. 1990. Modeling transient storage and nitrate uptake kinetics in a flume containing a natural periphyton community. Water Resources Research 26: 505-515.
Kishi D, Murakami M, Nakano S, Maekawa K. 2005. Water temperature determines strength of top-down control in a stream food web. Freshwater Biology 50: 1315-1322.

Liu W-Y, Gantt RT, Klemas A. 1987. Measurement of the surface emissivity of turbid waters. Remote Sensing of Environment 21: 97-109.

Loheide SP II, Gorelick SM. 2005. A local-scale high-resolution evapotranspiration mapping algorithm (ETMA) with hydroecoloogical applications at riparian meadow restoration sites. Remote Sensing of Environment 98: 182-200.

Masuda K, Takashima T, Takayama Y. 1988. Emissivity of pure and sea waters for the model sea surface in the infrared window regions. Remote Sensing of Environment 24: 313-329.

MODIS Emissivity Library. 2007. http://www.icess.ucsb.edu/modis/ EMIS/html/em.html, Last accessed 7th June 2007.

Morin A, Lamoureux W, Busnarda J. 1999. Empirical models predicting primary productivity from chlorphyll a and water temperature for periphyton and lake and ocean phytoplankton. Journal of the North American Benthological Society 18: 299-307.

O’Neill PE, Jackson TJ. 1990. Observed effects of soil organic matter content on the microwave emissivity of soils. Remote Sensing of Environment 31: 175-182.

Poole GC, Berman CH. 2001. An ecological perspective on in-stream temperature: natural heat dynamics and mechanisms of human-caused thermal degradation. Environmental Management 27: 787-802.

Rice RW. 2004. Emittance factors for infrared thermometers used for wood products. Wood and Fiber Science 36: 520-526.

Selker JS, Thevenaz L, Hendrik H, Mallet A, Luxemburg W, van de Giesen N, Stejskal M, Zeman J, Westhoff M, Parlange MB. 2006. Distributed fiber-optic temperature sensing for hydrologic systems. Water Resources Research 42: W12 202, Doi:10·1029/2006WR005326. Torgersen CE, Faux RN, McIntosh BA, Poage NJ, Norton DJ. 2001. Airborne thermal remote sensing for water temperature assessment in rivers and streams. Remote Sensing of Environment 76: 386-398.

Uehlinger U, Malard F, Ward JV. 2003. Thermal patterns in the surface waters of a glacial river corridor (Val Roseg, Switzerland). Freshwater Biology 48: 284-300.

Ward JV. 1985. Thermal characteristics of running waters. Hydrobiologia 125: $31-46$.

Webb BW, Zhang Y. 1999. Water temperatures and heat budgets in Dorset chalk water courses. Hydrological Processes 13: 309-321. 